\title{
DEVELOPMENT OF AN E-LEARNING PLATFORM FOR IMPROVING AND ASSESSING THE STUDENT OUTCOMES IN ELECTRICAL ENGINEERING
}

\author{
Joan Pons-Llinares ${ }^{1}$, Soledad Bernal Pérez ${ }^{2}$, Tania García Sánchez ${ }^{2}$, Jorge \\ Bonet-Jara ${ }^{2}$, Roser Sabater i Serra ${ }^{2}$ \\ ${ }^{1}$ Instituto de Ingeniería Energética, Universitat Politècnica de València (SPAIN) \\ ${ }^{2}$ Departamento de Ingeniería Eléctrica, Universitat Politècnica de València (SPAIN)
}

\begin{abstract}
In the European Higher Education Area, the concept of 'education' can be defined as a process that facilitates learning. The process will culminate successfully if our students have really learned and not necessarily because we have taught them. Taking into account the educational environment in which we are immersed, the learning process must be turned into a process where the students become aware of their goals and the teacher is transformed into a guide that escorts the students towards the achievement of the objectives. The organization of teaching in this environment involves developing new conceptualizations and methodologies, which can be applied jointly to classical methodologies, acting in a complementary and also synergistic manner.

Currently, all academic institutions use virtual campus platforms for educational purposes. At the Universitat Politècnica de València (Spain), this virtual system can be used as a repository of academic material but also has tools for the development of applications based on e-learning. In the present paper, an e-learning platform has been designed for students of electronic engineering that guide the learners to understand theoretical concepts, integrate theory and practice, and apply knowledge and skills to develop a viable solution to specific problems. The importance of defining and assessing learning outcomes, that is, the competences that students should have acquired and can use, have also been considered. To achieve this goal, a problem-based learning approach has been used so the students learn to identify and interpret data and design strategies to solve problems applying concepts of analysis of electrical circuits.

First, the most relevant competences that the students must achieve has been analysed ('Knowledge and use of the principles of theory of circuits and electric machines', 'Applied knowledge of electrical engineering' and 'Analysis and resolution of problems'). Based on them, a battery of tests and tasks has been designed, in order to reinforce the theoretic concepts and analyse and solve problems. The 'Test \& Quizzes' tool of the system has been used to develop the e-learning platform, in which selfevaluation has been also integrated in order to become an effective instrument for learning. The focus has been put on the design of the strategy in relation to the competences that students should acquire, the experience gained during the development of the e-learning platform and the students' satisfaction after the implementation.
\end{abstract}

Keywords: e-learning, problem-based learning, problem resolution skills.

\section{INTRODUCTION}

The European Higher Education Area (EHEA) and Bologna process is the result of the political will of 48 European countries with the aim to implement reforms on higher education on the basis of common values, such as autonomy for institutions and academic freedom. Through this process, countries, institutions and stakeholders of the European area continuously adapt their higher education systems making them more compatible and strengthening their quality assurance mechanisms. The framework of the European Higher Education Area (EHEA) defines three main objectives: a) To achieve a European University System with comparable and compatible qualifications, b) To create a common system to estimate the number of credits based on students workload and learning outcomes (European Credit Transfer System) and c) To promote mobility between students and staff (http://www.ehea.info/).

In order to comply these objectives, traditional learning systems must evolve to become much more flexible and open, so that learners can have individual learning pathways adequate to their needs and interests. The learning process must move on into a process where the students become aware of 
their goals and the teacher is transformed into a guide that escorts them towards the achievement of the stablished objectives. The organization of teaching in this environment involves developing new conceptualizations and methodologies, which can be applied jointly to classical methodologies, acting in a complementary and also in a synergistic manner.

In this context, the use of e-learning has become an essential base for the Education System, facilitating a 'flexible' learning and also the 'virtual' mobility between students and professors [1], [2]. E-learning can be defined as the learning experience involving the use of Internet technologies to deliver a broad array of solutions that enhance knowledge and performance. In this definition, computer networks or webs as the delivery or mediation mechanisms are included [3].

The perceptions of learning are undergoing a distinctive transformation. Training should no longer only focus on the act of training but have to demonstrate a positive impact on outcomes or performance [3], [4]. Students demand access to learning anytime, anywhere and on their terms, so a migration of information to online environments is required. Even though traditional classroom learning currently continues to have an important role, digital classrooms (a major e-learning tool) are increasing in recent years and this trend is expected to continue. It is important to note that e-learning is asynchronous in nature. Asynchronous e-learning refers to a "learning platform" that is pre-recorded or available to learners at any time and from any location [3] [5]. The use of technological tools, involved in the concept of e-learning, can play a synergistic role in facilitating learning. Blended classes, or 'blended learning', with the combination of technology (e-learning) and classroom-based learning are becoming quite popular as a form of training [5], [6]. Additionally, there is growing recognition that learning is a continuous, life-long process [4].

The main goal of engineering education is to produce broad-based, flexible graduates who can think in an integral manner, solve problems and be life-long learners [7], [8] The traditional lecture methodology within engineering education is deductive, beginning with the theory and progressing towards application of the theory. This pedagogical approach fails because the knowledge is not grounded. The learning environment is too abstract and dull and, as a consequence, the students get bored and lose motivation. Using a more learner-centered teaching, such as learning-oriented assessment [9] or problem-based learning can overcome this problem. Problem-based learning in engineering fits because it allows the students to develop skills to solve complex problems, increasing critical thinking [7].

Problem-based learning (PBL) can be defined as an instructional (and also curricular) learnercentered approach that empowers learners to conduct research, integrate theory and practice, and apply knowledge and skills to develop a viable solution to a defined problem [10]. In this learning approach, learners are presented with a problem in order to activate their prior knowledge [11] and whereby the problem is the starting-point of the learning process [12]. PBL is a teaching and learning methodology that by means of problems initiate, focus, motivate and promote students understanding of the theoretical concepts and also promoting the development of attitudes and professional skills. This methodology was developed at the McMaster University Medical School in the 1960s in the context of physician training; however, it has spread to other disciplines such as business administration and also engineering [13]. In doing so, PBL has to adapt to the different teaching contexts and, as a consequence, has adopted different formats [8], [14].

Academic institutions use virtual campus platforms for educational purposes. The virtual system (campus) of the Universitat Politècnica de València (Spain) can be used as a repository of academic material but also has tools for the development of applications based on e-learning. In this paper, the design of a new e-learning platform for students of the subject "Electrical Technology" is presented. This subject is included in the Bachelor's Degree in Industrial Electronics and Automation Engineering and taught in first semester of the second year. The aim of the e-learning platform designed is to guide students in the understanding of the concept related to electrical engineering by means of an approach based on problem-based learning. The students will learn to identify and interpret data and design strategies to solve problems applying concepts of analysis of electrical circuits.

A battery of questions/problems has been developed by means of the 'Test \& Quizzes' tool of the virtual system. This tool, integrated in the software of the platform, allows to generate random quizzes from a large variety of problem types. The quizzes enable the students to learn and ground the knowledge and also evaluate themselves. In the present paper, we present the e-learning platform, where the emphasis has been placed on the design of the strategy to develop the platform considering the competences that students should acquire. It is worth noting that the e-learning platform is also a source of relevant information about the student learning process over a period of time. Through this 
feedback, we will be able to adapt the content to those aspects in which a further need is identified, in order to fulfil the objectives and competences proposed in the academic curriculum.

\section{METHODOLOGY}

The present section describes the methodology followed to design, build and implement the e-learning platform. The first step is to analyse the objectives that need to be achieved. The second step is describing the virtual campus platform that will be used as starting point to develop the e-learning platform. The third and last step are the characteristics that the resulting e-platform should have in order to fulfil the objectives. In Section 3, the e-platform finally developed is described, showing its characteristics.

\subsection{Objectives}

The final objective is that, at the end of their academic life, our students have acquired a combination of attitudes, skills and competencies, which enable them to play a role in their industrial environment, and successfully develop a career, enjoying the pleasure of being an engineer. Hence, the role of the teacher is helping the student to develop the skills inherent to an engineer, in our case, specific of the subject "Electrical Technology", and instill passion for a unique world.

As mentioned, the subject is "Electrical Technology", of the "Degree in Industrial Electronics and Automation Engineering" taught at Universitat Politècnica de València. As shown in Table 1, the subject is divided into 8 didactic units, starting with an "Introduction to the analysis of electrical circuits" and finishing with "Fundamental principles of electrical machines". As it can be observed, is a broad program of Electrical Engineering, which goes from the principles, dealing with Kirchhoff Laws, passing through the description of power systems (protections and line design), till reaching electrical machines. Therefore, the general objective of the subject is, on a first stage, that the student assimilates the strategies related to Circuit Theory, that enables the analysis of electric circuits, in order to apply this knowledge to power systems, and, in a second stage, be able to perform a basic design of low voltage installations, and also understand the fundamental principles of electrical machines (transformers, generators and motors).

The first five didactic units are related to Circuit Theory. The subject starts with a refreshment of basic concepts, as current and voltage, and the basic laws for electric circuit analysis: Kirchhoff Laws and Ohm Law. Then, the strategies to solve direct and sinusoidal current circuits are presented (specially the symbolic method). Thevenin, Norton, and the rest of general theorems are studied, followed by an introduction to quadrupoles, which are especially important for electronic engineers when studying transistors. To end with Circuit Theory, three-phase systems are presented, both balanced and unbalanced, with the calculations of active, reactive and apparent power, and reactive compensation.

Table 1. Electrical Technology content and competences

\begin{tabular}{|c|c|c|}
\hline & & Subject: Electrical Technology \\
\hline Content & $\begin{array}{ll}\text { - } & \text { Introduct } \\
\text { - } & \text { Direct cu } \\
\text { - } & \text { General } \\
\text { - } & \text { Quadrup } \\
\text { - } & \text { Three-pr } \\
\text { - } & \text { The elec } \\
\text { - } & \text { Magnetic } \\
\text {. } & \text { Electrica } \\
\end{array}$ & $\begin{array}{l}\text { to the analysis of electrical circuits } \\
\text { ent and sinusoidal steady-state analysis } \\
\text { eorems in linear circuits } \\
\text { es } \\
\text { se systems and power factor correction } \\
\text { cal power system } \\
\text { circuits } \\
\text { nachines. Fundamental principles }\end{array}$ \\
\hline \multirow[t]{2}{*}{ Competences } & Specific & $\begin{array}{l}\text { Knowledge and use of the principles of circuit theory and electrical } \\
\text { machines } \\
\text { Applied knowledge of electrical engineering } \\
\text { Ability to handle specifications, regulations and mandatory } \\
\text { regulations fulfillment. }\end{array}$ \\
\hline & Transversal & - Analysis and problem solving \\
\hline
\end{tabular}


In the second stage, the electric power system is presented, specially studying its protection and control devices, together with the basic principles for the design of low voltage electric installations. The third and last stage deals with electrical machines, starting their study with the magnetic circuits, following with transformers, and ending with rotating machines and their fundamental principles.

Once there is a clear idea of the subject program, the competences can be presented and understood. The first competence that the students should acquire is "Knowledge and use of the principles of circuit theory and electrical machines". Indeed, the first fundamental learning outcome should be that the students know and are able to apply all the fundamental laws, theorems and strategies to analyse electric circuits, in order to apply this knowledge to electric installations, and the electric equivalent circuit of electrical machines.

The second competence ensures that the student reaches an "Applied knowledge of electrical engineering". This means that the student is able to use the theoretical knowledge to solve real life problems. For instance, once the student has learned how to analyse electric circuits, he can apply this knowledge to calculate three-phase shortcircuits, which are a key step to properly select protection devices. This is the first type of applied knowledge that the student acquires. Another example would be the calculation of the rated current consumed by an induction motor: this parameter is especially important when selecting the appropriate section for the line that feeds the motor.

The third competence is the "Ability to handle specifications, regulations and mandatory regulations fulfillment". This competence is specially related to the design of low voltage installations. For instance, the students must know that, when the line that feeds the motor is designed, its rated current must be multiplied by 1.25 . Furthermore, they must know how to handle the specific tables that enable to choose the section, as a function of the installation method and the insulation (usually, XLPE or PVC).

The question is: how the e-learning platform can help to achieve these competences? The e-learning platform should be able to guide the students through the understanding of the basic concepts, using numeric questions that enable a problem-based learning, till master the fundamental laws. In this sense, the platform should have a first level questions, where concepts are treated from a theoretical point of view, and then applied to simple cases. Then, yet in this first level, questions dealing with two concepts might be proposed. Finally, when the student is able to mix concepts to solve questions, he/she faces a second level with complex problems, where several concepts are involved. This progression would guide the students from more scientific problems, till more technological or applied ones. The platform should enable a gradual learning and self-assessment, with an individual time management, starting with the Circuit Theory, reaching the Electric Power Systems, till finally master the fundamental principles of Electric Machines.

\subsection{Virtual campus platform}

The virtual campus platform is a tool created by the university, which serves mainly as a repository of resources and communication between the professor and the students, with many other functionalities that can be used to enhance learning:

- Overview: in this first tab, the student can see the global announcements created by the different professors involved in the subject, the recent chat messages, the calendar with the different activities, deadlines, exams, etc., and the messages sent to specific groups.

- Teaching guide: in this second tab, the principal characteristics of the subject are summarized, beginning with the Faculty where the subject is taught, the bachelor's degree where it belongs, the department, area, number of credits, duration, type of subject, language of delivery, teachers involved and ending with a summary of the course description.

- Resources: the professors can upload the different materials, organized in folders, form pdf to video links.

- Drop Box: each student can upload in his personal folder the problems that must be delivered along the course; he will also receive in this personal folder the test results.

- Assignments: professor uploads the instructions for a problem / project that must be delivered, and assigns it to a certain group of students.

- Test and Quizzes: it enables the creation of question pools and assessments, with selfevaluations. This will be the base for the e-learning platform presented in this paper. 
- Gradebook Classic: all the numeric marks obtained by the students in the different assessments performed are saved in this tab.

- Management: only for professor, it enables to grade the assessments, obtain statistics, and look up the students lists with names, photos, e-mails and the rest of information.

- Calendar: it reflects the different activities, from deadlines to assessments, planned during the semester and related with the subject.

- Announcements: enables the professor to publish announcements for the entire set of students related with the subject.

- Messages: enables the professor to publish private messages addressed to specific groups of students.

- Forums: enables to set a topic, and start a discussion related to that topic.

- Chat Room: a general chat where everybody can express an opinion, give an information, ask a question, etc.

As mentioned, the "Test and Quizzes" tab will be the base for the e-learning platform presented in this paper.

\subsection{Desirable characteristics of the e-learning platform}

In order for the e-learning platform to be a tool that successfully helps the student to achieve his learning goals, it is desirable that it has the following general characteristics:

- Based on an e-virtual platform on the campus.

- Open.

- Available any time.

- Reflect on time the learning process.

- Available from any location.

- Flexible.

- Self-evaluation.

The platform must be based on the e-virtual platform: this indirectly enables some of remaining characteristics. First, it will be an open platform, available for any student enrolled in the subject. Second, the tool must available at any time: this enables that the student designs his individual pathway adequate to his/her needs. In this sense, it is important that the assessments have no time limit to be completed, and can be completed an arbitrary number of times, in order to enable the student to improve his marks. It would be desirable that every time a student performs a test, his/her result appears reflect, and the time evolution of his learning process can be analyzed. Nonetheless, the virtual platform used as starting point only keeps the last result. Therefore, the learning process can be analyzed only by looking at the time where the different tests have been performed.

It is also important that the platform is available from any location: in the European Higher Education Area, the mobility is very important, and students might need to take a subject from another country, in the case they were not able to take it on time. The flexibility is implicit in the openness and availability. Finally, the results for every assessment must have an explanation for every of its questions: otherwise, the student cannot enhance his/her results.

\section{RESULTS}

The base of the e-learning platform designed and built is a set of batteries of different types of questions. The questions are divided into two levels (Fig. 1):

- Level 1: Basic problems or questions related to fundamental concepts.

- Level 2: Complex problems that need the combination of several concepts to be solved. 


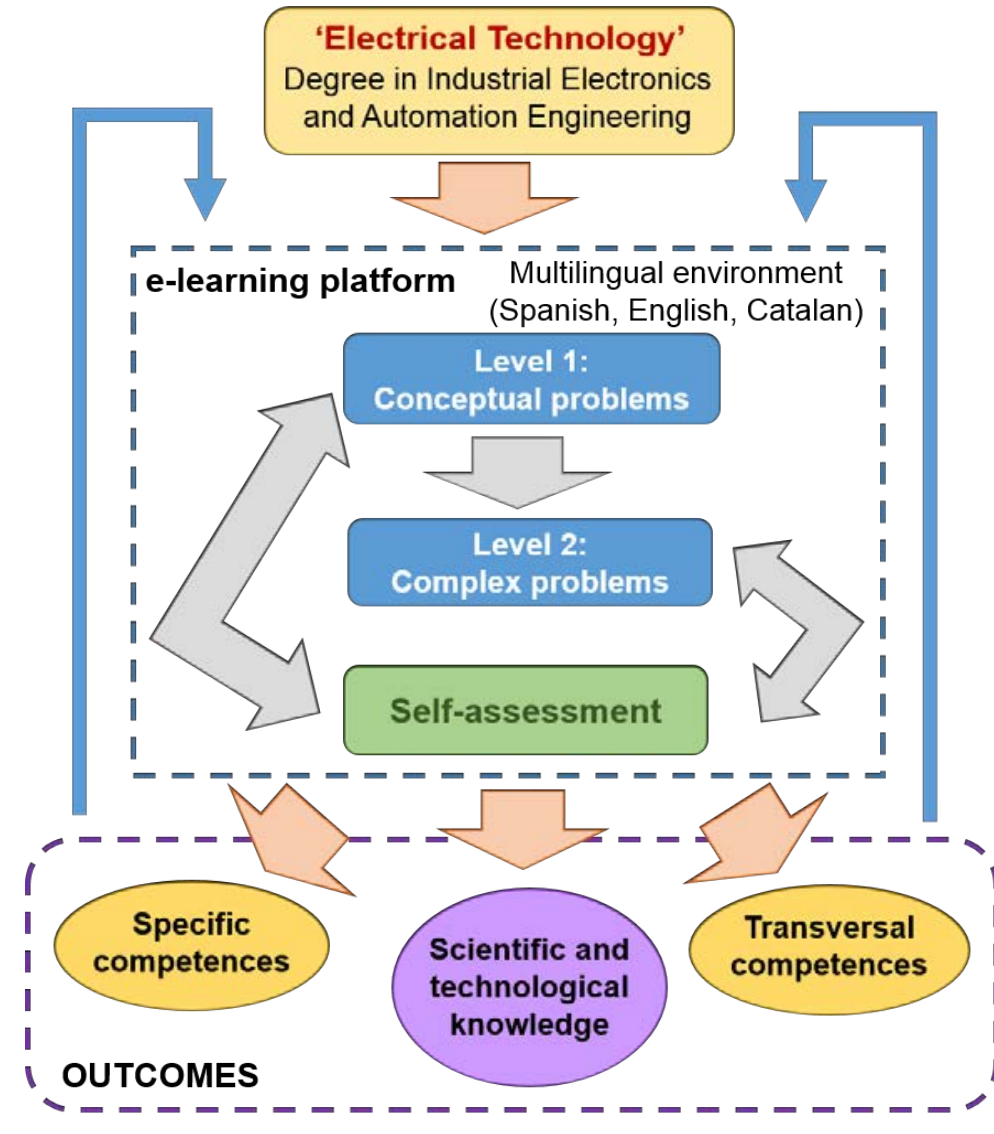

Figure 1.E-learning platform structure

The subject is taught by a set of five professors. Each of the professors takes care of at least one didactic unit. The first work step divides the didactic unit into a certain number of subunits, and each subunit divide it into a set of concepts that the student must learn: from definitions, specific properties up to one step calculations. Then, for every concept, the professor defines at least three questions which, from different points of views, try to assess if the student has learned that concept. The professor also writes an explanation of, in the case of a test question, the reasons for choosing the correct answer and dismiss the rest, and, in the case of a one-step calculation, explain the calculation process.

When every concept in a subunit has its battery of questions, an exam can be constructed, by putting together all the batteries. For instance, the subunit related to the automatic switch has a total of 20 batteries related to 20 concepts: from its definition, up to the calculation of its opening time under a certain current. As mentioned, each battery has at least 3 questions. When a student starts an exam, the e-learning platform chooses randomly one question for each battery, delivering a 20 questions exam assessing the 20 basic concepts of the automatic switch.

This exam, which will be centered in all the basic concepts of that subunit, can be performed by a student, during an unlimited time, and a number of unlimited times. The unlimited time to complete the exam is important: the time that the student takes to finish answering the test at this step of his learning process is not important, it is important that he can evolve within his own rhythm. Once the test is solved, the student might look at his answers, analyze which are right and which are wrong, and learn, looking at the professor's explanation, the reasons to choose the correct answer.

Then, once the student has learned from his errors, the exam can be repeated. The number of questions will be the same, one for each of the basic concepts of that subunit, nevertheless, since each question related to a concept is picked randomly from its related battery, the basic concepts will be reviewed from another perspective, really assessing if the student has understood this concept after performing his first test. Afterwards, the student can repeat the process as many times as he wants. The results shown when using the e-learning platform is that the students start with low marks, but gradually increase their results, till reaching a mark of even 10 out of 10 after three repetitions. 
Once the assessments related to concepts are completed, the student can face the resolutions of exams build using batteries of questions, each question dealing with a combination of two concepts, or with a process involving a couple or three calculations. This set of assessments will be placed also in the first level. If the student is able to combine the use of two concepts to solve a question, it can be concluded that the student understands the concepts and integrates theory and practice.

Finally, when this first level is achieved, the professors build a second level of questions divided into a certain number of batteries. In this second level, more complex problems are treated: the student must learn to identify the data that he needs to solve the question, and develop a viable solution to solve the problem. The result is a problem-based learning platform, that enables self-assessment, thanks to the explanations the professor has given to each question, and that can be analyzed by the students at the end of the test.

The university where this subject is taught, is in a region of Spain where two official languages coexist (Spanish and Catalan). Moreover, foreign students come also to study in this university. Therefore, each of the questions are written in three languages, as can be seen in Fig. 2, where each language is identified with a different color: green for English, red for Spanish and blue for Catalan. This way the student can find their questions quickly and easily.

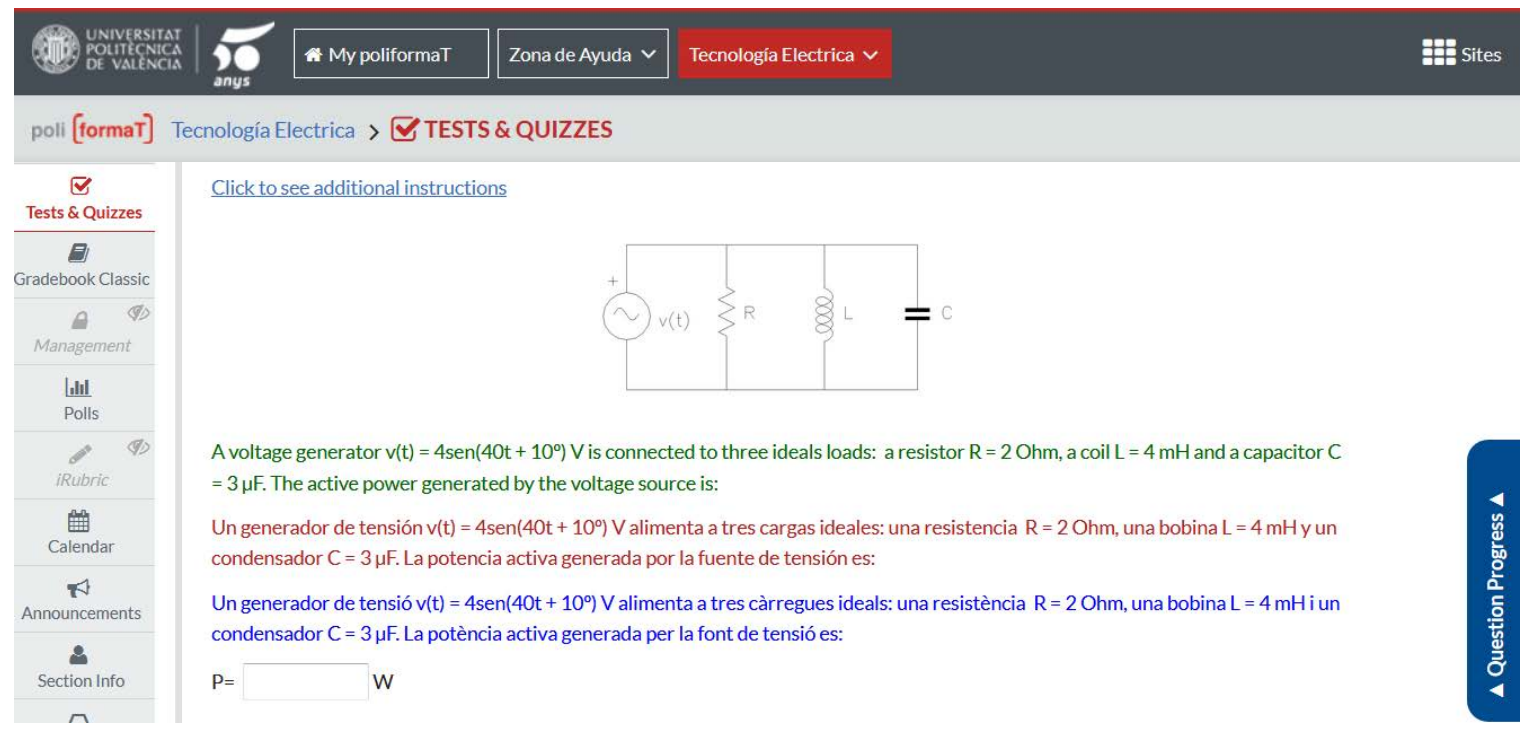

Figure 2. Multilingual question in the e-learning platform. Level 1: conceptual problem

\section{CONCLUSIONS}

An e-learning platform has been developed, based on a set of test batteries, which enables an ongoing process of learning, from the basic concepts, passing through the integration of theory and practice, till developing skills that enable solving complex problems. This way, once the principal theoretic and practical aspects of the subject have been presented by the teacher, an autonomous and flexible process of learning may start thanks to the use of this platform. The student can work autonomously, since the test batteries are perfectly organized, covering all the learning goals, automatically guiding the student. These learning goals, which have been previously specified, leading to the construction of the test batteries, are gradually achieved in a flexible time schedule that fits the student capabilities. Once a test is performed, the explanation of the correct answer given by the platform guides the student to the learning goal. In this regard, the teacher can complete this necessary guiding through tutorials. The student might repeat the same test, and the platform will select different questions involving the same concepts from a different perspective. This kind of "different repetition", facilitates learning of the principal concepts, which enables the student to go for test questions involving different theoretical and practice concepts, and finally solve complex problems. As it has been observed, the students might start with lower marks, but after completing twice a test, the concepts covered are learned, and the high results increase, even reaching the maximum marks. Finally, this platform, based on the use of internet technologies, enables also a mobile learning, which is a key factor in European Higher Education Area. 


\section{ACKNOWLEDGEMENTS}

This project is supported by Universitat Politècnica de València through the Project of Innovation and Educational Improvement Program (PIME 2018-2019/B26).

\section{REFERENCES}

[1] S. G. Va, M. A. Oliva, T. Torres, and C. Reding, "A technological acceptance of e-learning tools used in practical and laboratory teaching , according to the European higher education area," Behav. Inf. Technol., vol. 27, no. 6, pp. 495-505, 2008.

[2] L. Vicent, X. Àvila, J. Riera, D. Badia, J. Anguera, and J. A. Montero, "Appropriateness of elearning resources for the development of transversal skills in the new European Higher Education Area," in ASEE/IEEE Frontiers in Education Conference, 2006, pp. 6-11.

[3] M. J. Rosenberg, E-Learning: Strategies for Delivering Knowledge in The Digital Age. New York, NY: McGraw-Hill Professional Publishing, 2001.

[4] P. E. Sanderson, "E-Learning: strategies for delivering knowledge in the digital age," Internet High. Educ., vol. 5, no. 2, pp. 185-188, 2002.

[5] E. T. Welsh, C. R. Wanberg, K. G. Brown, and M. J. Simmering, "E-learning: emerging uses, empirical results and future directions," Int. J. Train. Dev., vol. 7, no. 4, pp. 245-258, 2003.

[6] M. Elliott, "The ASTD E-learning Handbook," in Blended learning: The magic is in the mix, A. Rossett, Ed. New York: McGraw-Hill: ASTD E-learning Handbook, 2002.

[7] M. A. L. U. \& C. F. B. Yadav, A. , Dipendra Subedi, "Problem-based Learning: Influence on Students' Learning in an Electrical Engineering Course," J. Eng. Educ., vol. 100, no. 2, pp. 253280, 2011.

[8] Halizah Awang and Ishak Ramly, "Creative thinking skill approach through problem-based learning: Pedagogy and practice in the engineering classroom," Int. J. Hum. Soc. Sci., vol. 3, pp. $1-14,2008$.

[9] D. Carless, "Exploring learning-oriented assessment processes," High. Educ., vol. 69, no. 6, pp. 963-976, 2015.

[10] N. Hosseinzadeh and M. R. Hesamzadeh, "Application of project-based learning (PBL) to the teaching of electrical power systems engineering," IEEE Trans. Educ., vol. 55, no. 4, pp. 495-501, 2012.

[11] H. G. Schmidt, J. I. Rotgans, and E. H. Yew, "The process of problem-based learning : what works and why," Med. Educ., vol. 45, pp. 792-806, 2011.

[12] E. D. E. Graaff and A. Kolmos, "Characteristics of Problem-Based Learning," Int. J. Eng. Educ., vol. 19, no. 5, pp. 657-662, 2003.

[13] J. E. Stinson and R. G. Milter, "Bringing Problem-based Learning to Higher Education," L. Wilkerson and W. H. Gijselaers, Eds. Jossey-Bass, San Francisco, 1996, pp. 33-42.

[14] L. Roberto and D. C. Ribeiro, "Electrical engineering students evaluate problem-based learning (PBL)," vol. 45, no. 2, pp. 152-161, 2008. 